\title{
Chitin synthase 1 plays a major role in cell wall biogenesis in Neurospora crassa
}

\author{
Oded Yarden and Charles Yanofsky \\ Department of Biological Sciences, Stanford University, Stanford, California 94305 USA
}

\begin{abstract}
In filamentous fungi, chitin is a structural component of morphologically distinct structures assembled during various phases of growth and development. To investigate the role of chitin synthase in cell wall biogenesis in Neurospora crassa, we cloned a chitin synthase structural gene and examined the consequences of its inactivation. Using degenerate oligonucleotide mixtures designed on the basis of conserved sequences of the Saccharomyces cerevisiae CHS1 and CHS2 polypeptides, a DNA fragment encoding a similar predicted amino acid sequence was amplified from $\boldsymbol{N}$. crassa genomic DNA. This product was used to probe $\boldsymbol{N}$. crassa libraries for a gene homologous to one of the yeast genes. Full-length genomic and partial cDNA clones were identified, isolated, and sequenced. The amino acid sequence deduced from a cloned 3.4-kb gene [designated chitin synthase 1 (chs-1)] was very similar to that of the $S$. cerevisiae CHS1 and CHS2 and the Candida albicans CHS1 polypeptides. Inactivation of the $N$. crassa chs-1 gene by repeat-induced point mutation produced slow-growing progeny that formed hyphae with morphologic abnormalities. The chs-1 ${ }^{\mathrm{RIP}}$ phenotype was correlated with a significant reduction in chitin synthase activity. Calcofluor staining of the chs-1 ${ }^{\mathrm{RIP}}$ strain cross-walls, residual chitin synthase activity, and the increased sensitivity of the chs-1 ${ }^{\mathrm{RIP}}$ strain to Nikkomycin $\mathrm{Z}$ suggest that $N$. crassa produces additional chitin synthase that can participate in cell wall formation.
\end{abstract}

[Key Words: Cell wall biosynthesis; fungal morphology; multiple chitin synthases]

Received July 22, 1991; revised version accepted October 7, 1991.

Chitin is one of the most abundant natural polymers. The biosynthesis and deposition of chitin involves the sequential biotransformation of simple metabolites, polymerization of biosynthetic intermediates, and extrusion of the product outside the plasma membrane (Cabib 1987; Cohen 1987; Bartnicki-Garcia 1989). Although abundant in arthropods, some fungi, and other eukaryotes, chitin is absent from plant and mammalian species (Muzzarelli et al. 1986). Thus, biosynthesis of chitin is an attractive target for the development of anti-pest/ anti-parasite drugs (Cohen 1987; Gooday 1989).

Chitin synthase (UDP-2-acetamido-2-deoxy-D-glucose : chitin 4- $\beta$-acetamidodeoxy-D-glucosyltransferase; EC 2.4.1.16) catalyzes the following reaction: $2 n$ uridine5 '-diphospho- $N$-acetylglucosamine (UDPGlcNAc) $\rightarrow 2 n$ $\mathrm{UDP}+[$ GlcNAc- $\beta-(1 \rightarrow 4)$ GlcNAc $] n$.

Chitin synthase activity is associated primarily with the membranous fractions of the fungal cell (Gooday 1977) and has been partially purified from yeast and filamentous fungi (Bartnicki-Garcia et al. 1978; Selitrennikoff 1979; Kang et al. 1984; Leal-Morales et al. 1988). To date, two genes encoding chitin synthase polypeptides have been identified in Saccharomyces cerevisiae (Bulawa et al. 1986; Silverman et al. 1988). Although chitin is believed to be an essential component of the cell wall,
S. cerevisiae CHSl has been shown to be dispensable (Bulawa et al. 1986; Cabib et al. 1989). CHS2 appears to be essential under certain conditions (Silverman et al. 1988). In some genetic backgrounds and environmental conditions, however, disruption of $\mathrm{CHS} 2$ results in abnormal morphology, not inviability (Bulawa and Osmond 1990). CHS1 and CHS2 of yeast have similar predicted amino acid sequences. Chitin synthase-like sequences have been deduced from the sequences of cloned fragments of other yeasts and several filamentous fungi (P. Robbins, pers. comm.), establishing the widespread existence of this enzyme in fungi. Since the pioneering work of Glazer and Brown (1957) on chitin synthesis in cell-free preparations of Neurospora crassa, the biochemical characteristics of fungal chitin synthases have been documented extensively (Cabib 1987; Cohen 1987; Gooday 1977; Gooday and Trinci 1980). Nevertheless, there is relatively little information on the genes responsible for chitin biosynthesis in filamentous fungi.

We have cloned, sequenced, and characterized a chitin synthase structural gene from $N$. crassa and designated it chs -1 . We used the repeat-induced point (RIP) mutation process to inactivate the chromosomal chs-1 locus. Strains lacking a functional CHS 1 have an abnormal growth pattern and morphology, in addition to exhibit- 
ing reduced levels of chitin synthase activity. Our findings suggest that chs-1 expression is necessary for normal cell growth and that $N$. crassa produces at least two chitin synthases.

\section{Results}

Cloning of the N. crassa chs-1 gene

Several pairs of degenerate oligonucleotide primers were designed on the basis of conserved amino acid sequences predicted from the S. cerevisiae CHS1 and CHS2 genes. These primers were used in polymerase chain reactions (PCRs) in an attempt to amplify corresponding regions of $N$. crassa genomic DNA. To allow amplification of sequences deviating slightly from the yeast consensus sequence, reactions were performed under low-stringency conditions $\left(1.5 \mathrm{~min}\right.$ at $92^{\circ} \mathrm{C}$, followed by 35 cycles of 2 min at $50^{\circ} \mathrm{C}, 5 \mathrm{~min}$ at $60^{\circ} \mathrm{C}$, and $1 \mathrm{~min}$ at $92^{\circ} \mathrm{C}$. When the 1280 and 1281 primer combination was used as a control mixture (Table 1; see Fig. 4, below), a single abundant $\sim 600$-bp product was obtained. A product was unexpected, as both primers were designed to anneal to the same DNA strand. Nonetheless, the amino acid sequence predicted from the nucleotide sequence of the cloned $\sim 600$-bp product showed striking similarity to those of both yeast chitin synthases. Subsequently, it was discovered that primer 1280 is complementary/with several mismatches) to a nucleotide sequence from another region of the $N$. crassa chs-1 gene /nucleotides

Table 1. Synthetic oligonucleotides

\begin{tabular}{|c|c|c|}
\hline $\begin{array}{l}\text { Oligo } \\
\text { number }\end{array}$ & Use & Sequence $^{b}$ \\
\hline 1280 & PCR & 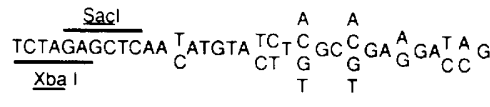 \\
\hline 1281 & PCR & 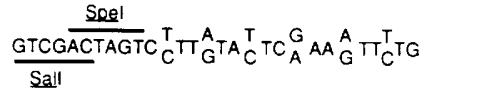 \\
\hline $\begin{array}{l}1990 \\
\text { (nucleotides } \\
697-673 \text { ) }\end{array}$ & Primer extension & $\frac{\text { CTAGTGGATCCATCATAGCCGTCGC }}{\text { BamHI }}$ \\
\hline $\begin{array}{l}2013 \\
\text { (nucleotides } \\
675 \cdot 698 \text { ) }\end{array}$ & $P C R$ & GACGGCTATGATGGATCCACTAGT \\
\hline $\begin{array}{l}2049 \\
\text { (nucleotides } \\
844-816)\end{array}$ & $\begin{array}{c}P C R \\
\text { Primer extension }\end{array}$ & GTTTTCGGAGAGGAAGGGACGTTGCGCAT \\
\hline $\begin{array}{l}2050 \\
\text { (nucleotides } \\
647-669 \text { ) }\end{array}$ & PCR & CGCAACCATGGCGTACCACGGTC \\
\hline
\end{tabular}

${ }^{a}$ Numbers in parenthesis designate nucleotide number and direction (based on the genomic nucleotide sequence presented in Fig. 3). Primers 1280 and 1281 were designed on the basis of conserved amino acid sequences, as marked in Fig. 4. Amino acid residues predicted to be encoded at the $5^{\prime}$ and $3^{\prime}$ ends of the product amplified using 1280 and 1281 (pCS12) are underlined in Fig. 4.

${ }^{b}$ Multiple lettering indicates oligonucleotide mixtures. Restriction sites for cloning PCR products are marked.
1390-1411; see Fig. 3, below), thus explaining the origin of the $\sim 600$-bp product.

Using the $\sim 600$-bp fragment (designated pCS12, Fig. 1) as a probe, a single genomic and several overlapping cDNA clones were identified and isolated from $N$. crassa genomic (Orbach et al. 1986) and cDNA (Orbach et al. 1990) libraries. From the genomic clone, 11-kb Apal and 4.3-kb BamHI fragments hybridizing to pCS12, containing the entire chs-1 gene, were isolated and subcloned. These clones, designated pOYA5 and pOY 30 , respectively (Fig. 1), were used in further analyses.

\section{Sequence of chs-1}

A 4.4-kb segment of pOYA5, containing the chs-1 gene, was sequenced completely on both strands. The molecular organization of the genomic segment containing chs-1 is presented in Figure 2. The complete nucleotide sequence of chs-1 and the predicted amino acid sequence of the CHS1 polypeptide are presented in Figure 3. The chs-1-coding region was located by comparing the predicted amino acid sequence with those of the two $S$. cerevisiae chitin synthases, using codon preferences of $N$. crassa. The nucleotide sequence immediately surrounding an initiation codon is believed to be important for efficient translation (Kozak 1986). The presumed chs-1 start codon segment (GCAACCATGG) is slightly different from the $N$. crassa consensus (A/GTCAA/ CAATGG) compiled for 20 genes (Roberts et al. 1988), but matches the sequence (GCCA/GCCATGG) conserved in higher eukaryotes (Kozak 1987). Two intervening sequences were tentatively identified on the basis of consensus 5'- and 3'-splice junction sequences /Orbach et al. 1986; Hager and Yanofsky 1990). The nucleotide sequence of a partial cDNA clone spanning $2.2 \mathrm{~kb}$ of the $3^{\prime}$ end of the gene and the untranslated region verified the nucleotide sequence of a major portion of the genomic clone, as well as the position and boundaries of the $3^{\prime}$ intron. The position and boundaries of the $5^{\prime}$ intron were verified by analyzing the sequence of two reverse transcriptase-polymerase chain reaction (RT-PCR) products obtained with primer combinations 2049-2050 and 2013-2049 (Table 1). A CCAAT box and polyadenylation signal sequence (Proudfoot and Brownlee 1976) are present (Figs. 2 and 3). The $5^{\prime}$ end of the chs-1 transcript (Fig. 3) was determined (data not shown) by primer extension techniques (Sambrook et al. 1989), using the primers shown in Table 1 . The 3 '-end designation was based on the common poly(A) addition site in two independent cDNA clones.

\section{Chromosomal localization of chs-1}

Restriction fragment length polymorphism (RFLP) analyses were used to map chs-1. Of several restriction enzymes used (BamHI, EcoRI, HindIII, KpnI, PstI, and $X$ hoI), only Xhol and PstI revealed polymorphisms in the vicinity of chs-1 in N. crassa of Oak Ridge and Mauriceville backgrounds. PstI was used to digest DNA from progeny of the "small cross" (Metzenberg et al. 1985). 


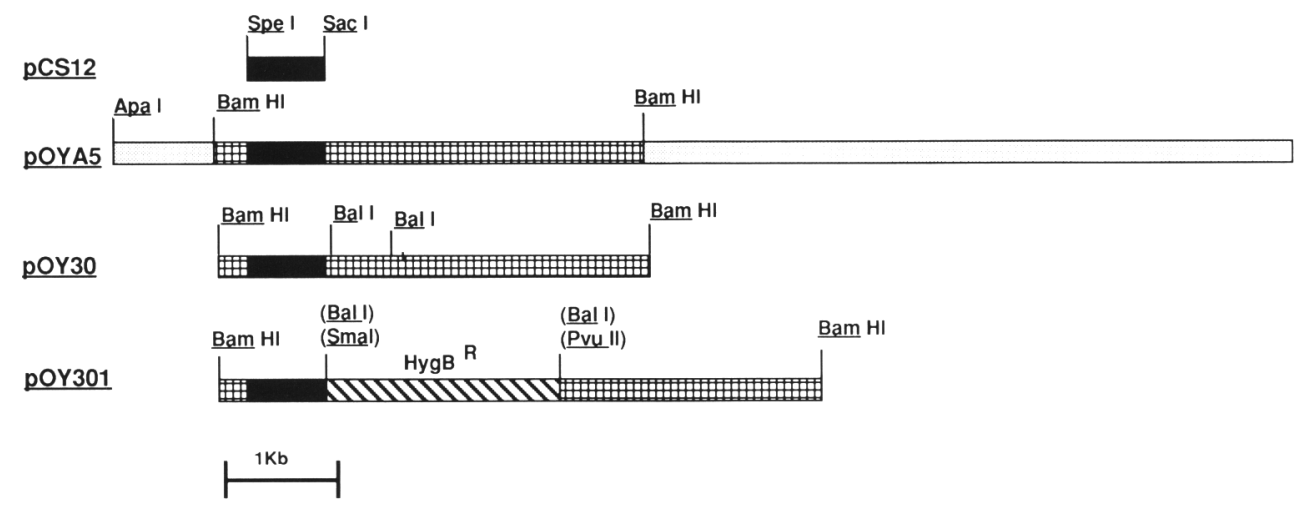

Figure 1. Clones and constructs used in this study. pCS12 is a cloned N. crassa genomic DNA product amplified by low-stringency PCR. pOYA5 is an ApaI fragment obtained from the DNA of an individual plaque from the Orbach $\lambda J 1 N$. crassa genomic library, identified after probing with pCS12. pOY30 is a $3.6-\mathrm{kb}$ BamHI subclone of pOYA5, identified by hybridization with pCS12. It was used for construction of pOY301. pOY30l is pOY30 containing a 4.3-kb PvuII-SmaI fragment of pDH25, consisting of the hygromycin phosphotransferase gene driven by the $A$. nidulans trpC promoter region (Cullen et al. 1987).

Subsequent probing with a hexamer-labeled Pst digest of pOY30 located chs-1 between Fsr-9 and am, on linkage group V (data not shown).

\section{CHS1 amino acid homology}

chs-1 encodes a predicted 961-residue polypeptide with a calculated mass of $107 \mathrm{kD}$ and a $\mathrm{pI}$ of 8.8 . The predicted amino acid sequence of $N$. crassa CHS1 is $37 \%, 39 \%$, and $40 \%$, identical to those of $S$. cerevisiae $\mathrm{CHS1}$ and CHS2 and Candida albicans CHS1, respectively (Fig. 4). The calculated $\mathrm{pl}$ of the entire N. crassa CHS1 polypeptide is similar to those calculated for $S$. cerevisiae CHS2 $(\mathrm{pI}=9.1)$ and $C$. albicans $\mathrm{CHS} 1(\mathrm{pI}=8.7)$ but differs from the value calculated for the $S$. cerevisiae CHS 1 polypeptide $(\mathrm{pI}=5.8)$. Nonetheless, the calculated $\mathrm{pI}$ value of the amino-terminal end 230 residues of the $N$. crassa CHS1 polypeptide $(\mathrm{pI}=5.3)$ resembled more closely the calculated value for the amino-terminal region of the $S$. cerevisiae CHS1 polypeptide $(\mathrm{pI}=4.5)$ than that of the same region of CHS2 (pI $=10.4)$. Hydrophilicity analysis predicts a hydrophilic region at the amino terminus (spanning residues $1-230$ ) and a hydrophobic region at the carboxyl terminus (residues 560961 of the polypeptide; Fig. 5). The presence of several putative membrane-spanning domains near the carboxyl

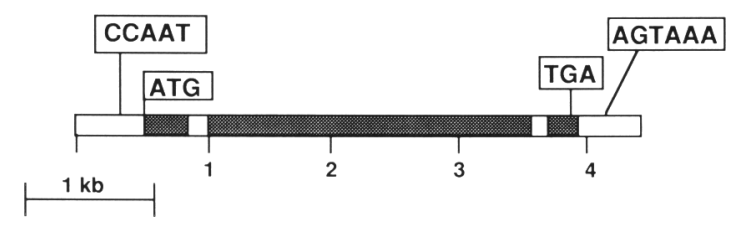

Figure 2. Molecular organization of chs-1. Schematic diagram of a portion of pOYA5 that includes the chs-1 gene. CCAAT, translation start, stop, and polyadenylation sequences are shown. (Shaded bars) Coding region; (open bars) noncoding region. terminus is consistent with the membrane association of chitin synthase activity (Duran et al. 1975; Peberdy and Moore 1975). Two potential N-glycosylation sites are present (Pless and Lennarz 1977) at amino acid residues 544 and 788 (Fig. 3).

\section{Functional analysis of chs-1}

In view of the finding that CHS1 of $S$. cerevisiae is nonessential, we disrupted chs-1 of $N$. crassa. The gene was inactivated by using the RIP process (Selker 1990), which results in many premeiotic GC $\rightarrow$ AT base-pair transitions in duplicated DNA sequences. A $4.3-\mathrm{kb}$ fragment of chs-1 was transformed into a wild-type strain of $N$. crassa. The DNA used for transformation [designated pOY301 [Fig. 1)] consisted of pOY30 interrupted at the 2258 Ball site (Fig. 3) by insertion of a 4.1-kb PvuII-SmaI fragment, encoding an expressed $h p h$ gene isolated from pDH25 (Cullen et al. 1987). This construction permitted selection of transformants based on hygromycin resistance. One transformant (T-36), containing a single ectopic copy of pOY301 (Fig. 6A), was crossed with another transformant (T-51), of the opposite mating type. Among the viable ascospores isolated from this cross, $\sim 41 \%$ exhibited very slow growth. Southern blot analysis provided evidence that in these progeny chs-1 had been subjected to RIP (Fig. 6A); restriction sites were missing from both the resident and the ectopic chs-1 gene copies. One of the progeny cultures that had undergone RIP /chs$1^{\mathrm{RIP}}$ | was chosen for further analysis. The absence of chs-1 message, as determined by Northern blot analysis (Fig. 6B), provided additional evidence for the extensive alteration of the chs-1 gene in this strain. The absence of the chs-1 RNA was specific, as similar tub-2 RNA levels were detected in RNA samples from both the wild-type and chs $-1^{\mathrm{RIP}}$ strains. When the chs-1 $1^{\mathrm{RIP}}$ strain was crossed with a wild-type strain, a $1: 1$ ratio of wild-type/ chs $-1^{\mathrm{RIP}}$ progeny was observed; this is typical of single locus alterations. To demonstrate that the altered phe- 


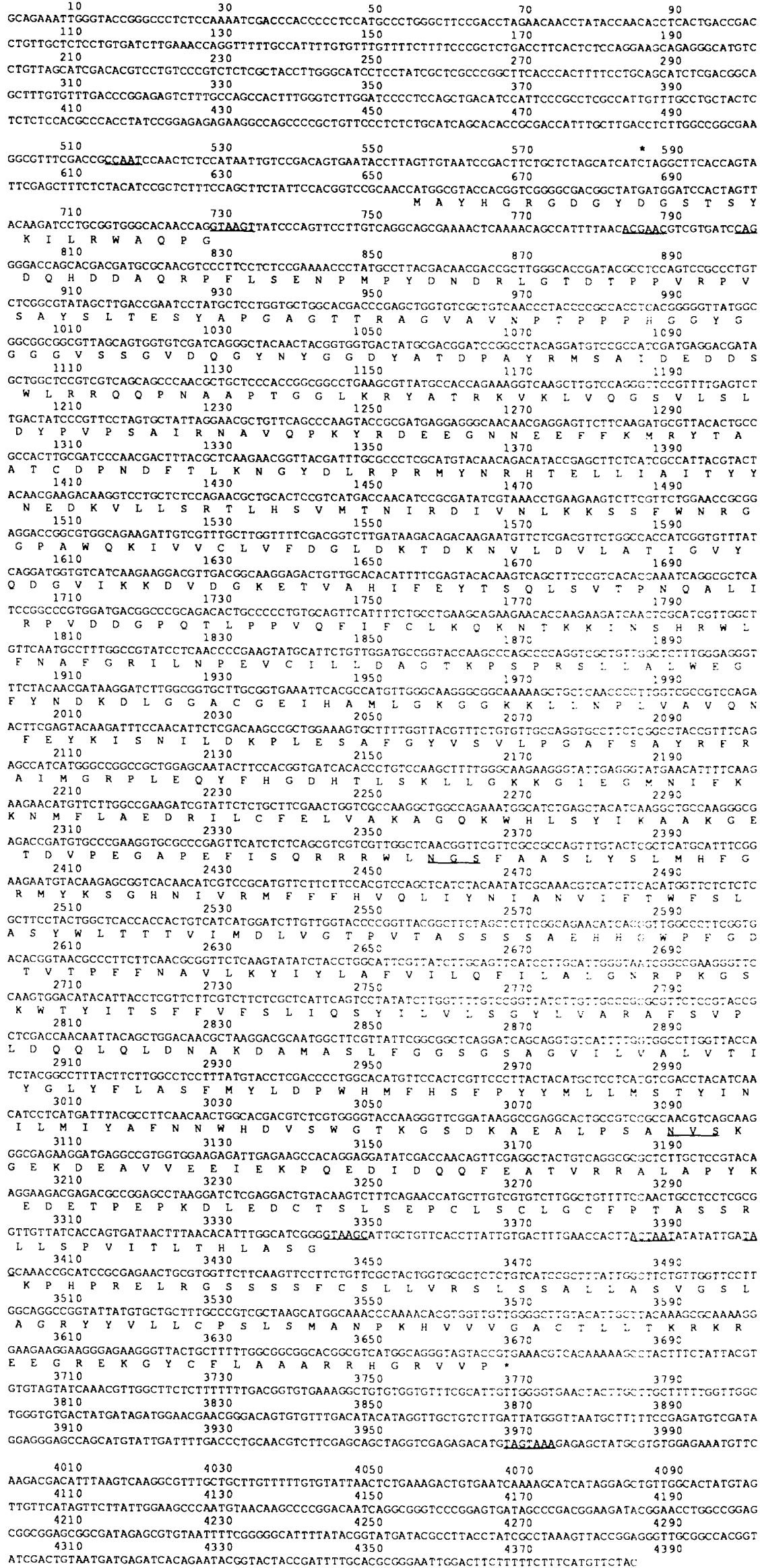

Figure 3. Complete nucleotide sequence for the $N$. crassa chs-1 gene and flanking regions and the predicted amino acid sequence of CHS1. The CCAAT sequence is underlined. The transcription initiation site is marked by an asterisk $(*)$. Conserved intron boundary and presumed lariat sequences are underlined, as is the conserved polyadenylation signal. Two potential N-glycosylation amino acid sequences are underlined. 


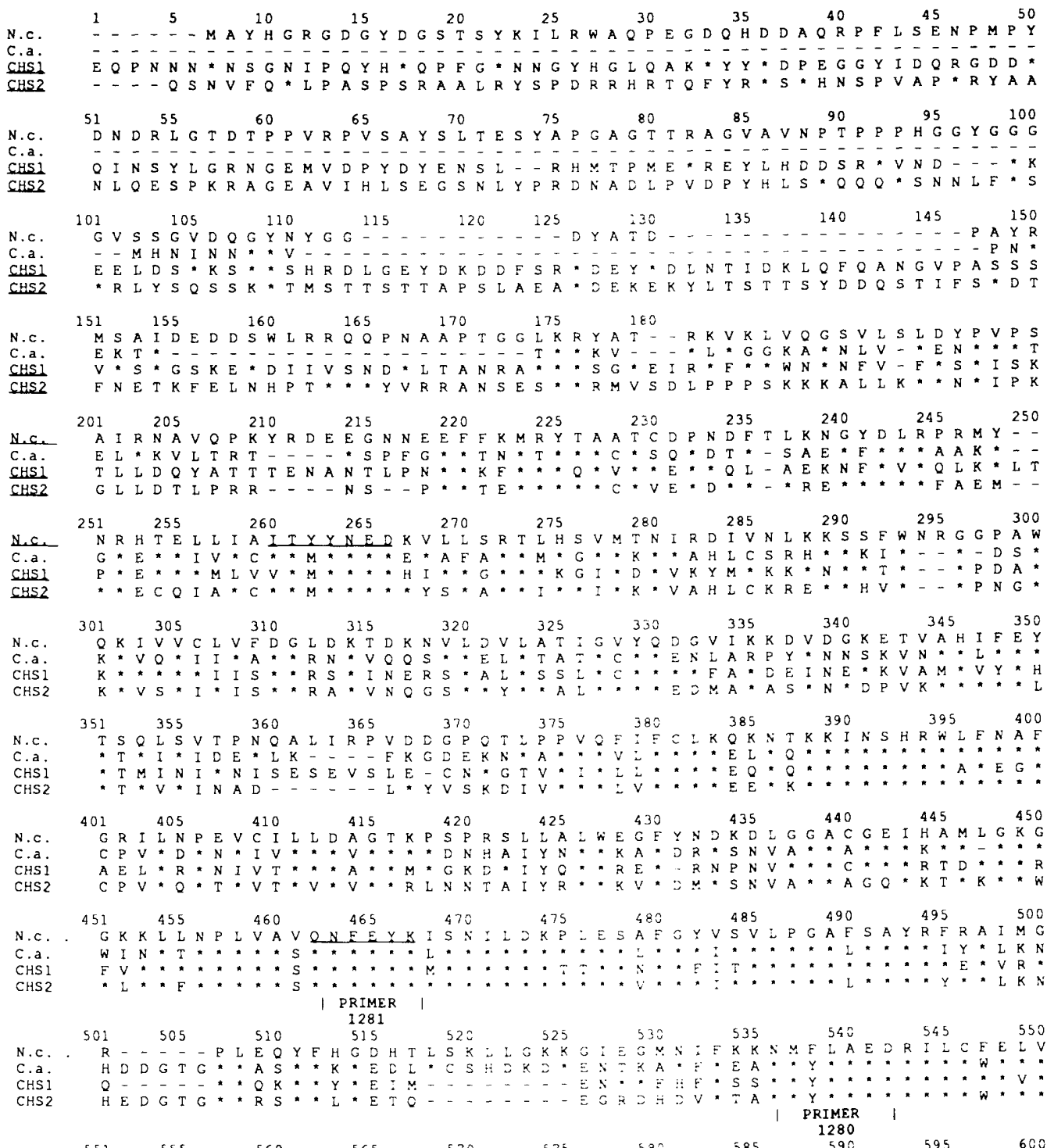

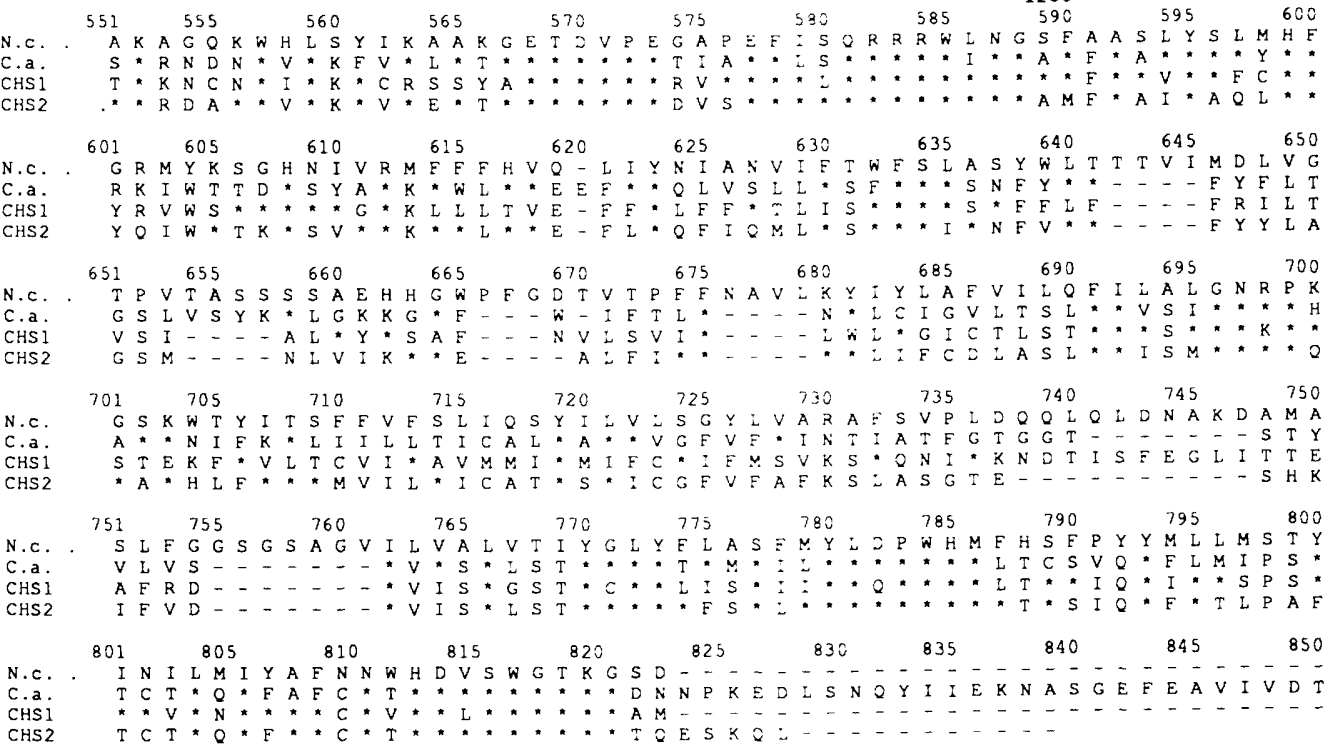

Figure 4. (See facing page for legend.) 


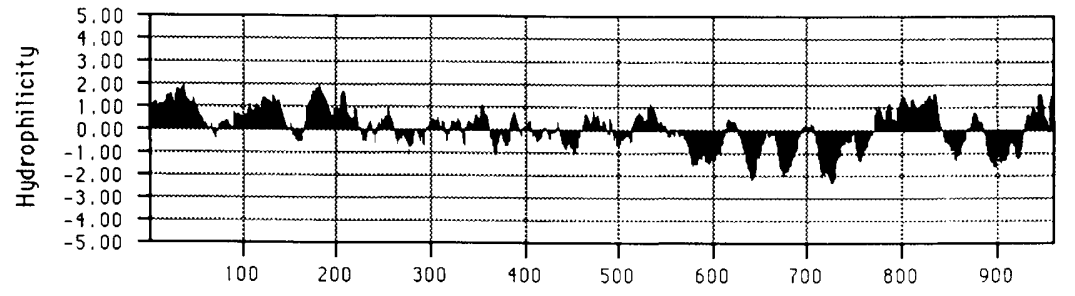

Figure 5. Hydropathicity plot for the predicted amino acid sequence of the $N$. crassa CHSl polypeptide. Peaks above the axis are hydrophilic regions; those below the axis are hydrophobic. Note the hydrophobic segments beyond residue 550 . notype of the chs-1 ${ }^{\text {RIP }}$ strain was the result of inactivation of chs-1, we performed a complementation experiment with pOYA5 (containing the genomic copy of chs1) and pMP6 (for transformant selection). Among 60 hygromycin-resistant transformants analyzed, 28 had a morphology that was indistinguishable from that of wild type. This result provides evidence that the transformation with pOY301, as well as the RIP process, did not affect other sequences that are involved in the determination of hyphal morphology.

\section{chs-1 ${ }^{R I P}$ morphology}

Growth of the chs $-1^{\text {RIP }}$ strain on both solid and liquid media was significantly slower than that of wild type. To quantitate the difference in hyphal elongation, the rate of radial growth was measured from a mycelial disc placed in the center of a $150-\mathrm{mm}$-diam. petri dish. Within $24 \mathrm{hr}$ (at $34^{\circ} \mathrm{C}$ ), the wild-type strain had grown to a $64-\mathrm{mm}$ radius, covering most of the dish. During the same period, the chs-1 ${ }^{\text {RIP }}$ strain had grown to only a $14-\mathrm{mm}$ radius. Even after 1 week of growth, the chs-1 RIP colony had not equaled the radial growth of the 24-hr-old wild-type strain (Fig. 7). Furthermore, the density of hyphal growth was sparse, and there was little evidence of conidiation. Thus, chs- $1^{\text {RIP }}$ lacked the confluent mycelial mat that is typical of wild-type growth. Supplementing either solid or liquid medium with $1 \mathrm{M}$ sorbitol as an osmotic stabilizer had no effect on $c h s-1^{\text {RIP }}$ growth /data not shown).

Microscopic examination of cultures grown in liquid medium revealed extensive hyphal swelling and other hyphal abnormalities in the chs-1 ${ }^{\text {RIP }}$ strain, when compared with wild type (Fig. 8A-E). In some instances, severe swelling of the hyphae of germinating conidia was observed (Fig. 8D). When grown on solid media, long thin aerial hyphae were apparent, and frequently, the hyphal tips had deteriorated (Fig. 8E). However, subjecting chs-1 to RIP did not affect cross-wall formation or abundance. This was demonstrated by Calcofluor staining (Fig. $8 \mathrm{~F}, \mathrm{G})$. When chs $-1^{\mathrm{RIP}}$ cultures grown on solid media matured to the conidiation phase, microscopic examination revealed that conidia, as well as major and minor conid- iophore constrictions, were morphologically similar to those of wild type (data not shown).

\section{Chitin synthase activity in the chs- $1^{\text {RIP }}$ strain}

Chitin synthase enzyme activity was measured as the incorporation of UDP $\left[1-{ }^{14} \mathrm{C}\right] \mathrm{GlcNAc}$ into an insoluble product. The enzyme activity was measured in cell-free extracts prepared from wild-type and chs-1 $1^{\text {RIP }}$ strains. Chitin synthase activity in the chs $1^{\text {RIP }}$ extracts was found to be 7 - to 20 -fold lower than in wild-type extracts (Fig. 9). Variation among duplicate samples prepared from each extract source did not exceed $12 \%$. Attempts to determine the fractions of chitin synthase that were susceptible to activation by proteolysis were inconclusive, as activation was too variable from sample to sample. Our findings are consistent with the wide range of variation in the effect of proteases on the activity of $N$. crassa chitin synthase activity, which has been reported previously (Bartnicki-Garcia et al. 1978; Arroyo-Begovich and Ruiz-Herrera 1979). Residual chitin synthase activity was observed in all chs- $1^{\text {RIP }}$ extracts, suggesting that other chitin synthases are active in the chs-1 ${ }^{\text {RIP }}$ strain. To confirm that the chs-1 ${ }^{\text {RIP }}$ strain was deficient in chitin synthesis, we determined the sensitivity of the chs $-1^{\text {RIP }}$ strain to Nikkomycin Z, a competitive inhibitor of chitin synthase (Gow and Selitrennikoff 1984). When grown in the presence of the inhibitor, the chs $-1^{\text {RIP }}$ strain was significantly more sensitive to the drug than was wild type (Fig. 10A). To establish that the hypersensitivity of the chs-1 ${ }^{\text {RIP }}$ strain was specific to Nikkomycin, the comparative sensitivity of wild-type and $c h s-1^{\text {RIP }}$ strains to the microtubule inhibitor Benomyl was tested. Both strains were equally sensitive to Benomyl (Fig. 10B).

\section{Discussion}

chs-1 from $N$. crassa, a member of a chitin synthase gene family, has been cloned and characterized. We have shown that chs-1 is dispensable, yet its product is required for normal cell growth. The similarity between the predicted amino acid sequence of CHS1 of $N$. crassa

Figure 4. Multiple sequence alignment of four predicted chitin synthase polypeptides. The comparison was of residues 1-780 of $N$. crassa CHS1 (N.c.), residues 200-975 of $S$. cerevisiae CHS1 (CHS1), residues 50-815 of S. cerevisiae CHS2 (CHS2), and residues 1-741 of Candida albicans CHS1 (C.a.). Asterisks (") mark amino acid residues identical to the $N$. crassa polypeptide; dashes mark gaps. Regions used for the design of degenerate oligonucleotide primers 1280 and 1281 (Table 1) are indicated. Amino acid residues predicted to be encoded at the $5^{\prime}$ and $3^{\prime}$ ends of the PCR product obtained (pCS12, Fig. 1) are underlined. 


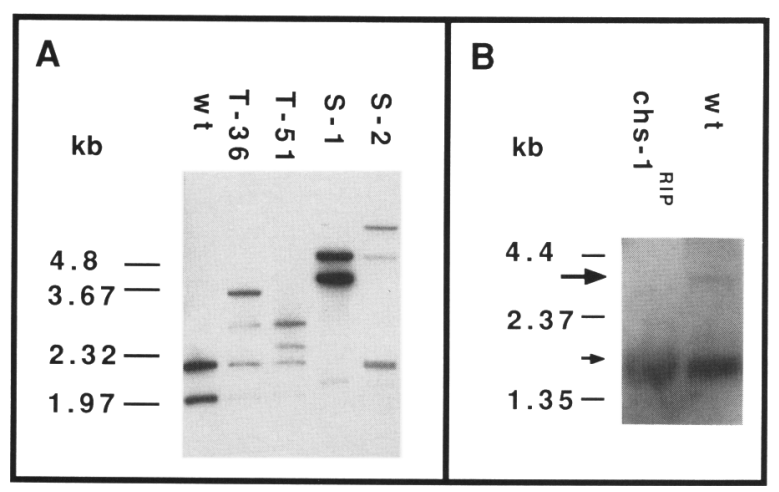

Figure 6. Molecular analysis of chs-1 DNA and transcript in wild type, pOY301-transformed, and chs-1 ${ }^{\text {RIP }}$ strains of $N$. crassa. $(A)$ Southern blot analysis of BamHI-EcoRV digests of genomic DNA isolated from wild type (wt), two isolates that were transformed with pOY301 (T-36, T-51), and two chs-1 $1^{\mathrm{RIP}}$ progeny ( $S-1, S-2$ ) from a cross between $T-36$ and T-51, exhibiting slow growth and abnormalities in hyphal morphology. The probe used was a hexamer-labeled BamHI digest of pOY30. (B) Northern blot analysis of total RNA from wild type (wt) and the S-1 slow-growing progeny from the T-36-wild-type cross. The blot was probed with a hexamer-labeled BamHI digest of pOY30 (for chs-1) and a 1.2-kb SacI digest of pBT3 (for tub-2). The large arrow indicates the position of the chs-1 message; the small arrow indicates the position of the tub-2 message.

and those of the yeast chitin synthases permitted us to detect and clone the $N$. crassa gene.

Hydropathy plots suggest that the chitin synthase polypeptides of $N$. crassa, S. cerevisiae, and C. albicans have similiar characteristics throughout their length. However, Silverman (1989) has found a significant difference between the calculated pI values of the aminoterminal regions of the two $S$. cerevisiae chitin synthase polypeptides. We performed a similar comparison between the $N$. crassa and yeast chitin synthases. Because the similarities and differences between the various polypeptides, on the basis of calculated $\mathrm{pI}$ values, are not uniform throughout the length of the polypeptides, additional criteria must be applied before we can determine which synthases perform the same functions.

The RIP phenomenon was used to inactivate chs-1. The slow growth and abnormal swelling of chs-1 ${ }^{\text {RIP }}$ hyphae demonstrate that chs-1 plays a major role in hyphal growth. Conidia do not seem to be affected by chs-1 disruption; therefore, an additional chitin synthase may be primarily responsible for chitin deposition during sporulation. Reduction in the chitin content of the primary cell wall is probably responsible for the gross hyphal alterations observed in the chs-1 ${ }^{\mathrm{RIP}}$ strain. Lack of the primary chitin building block (although it constitutes only $10 \%$ of the fully assembled cell wall) could lead to alteration of the architecture of the fungal cell wall, resulting in the observed morphologic abnormalities. Nonetheless, lack of CHS1 activity does not render the organism inviable. Using Calcofluor staining of the chs-1 ${ }^{\mathrm{RIP}}$ strain, what appears to be normal deposits of chitin were detected in cross-walls, where chitin is the major component (Hunsley and Gooday 1974), and in conidial septa. This finding is supported by our detection of residual chitin synthase activity in this strain (which is also hypersensitive to the chitin synthase inhibitor Nikkomy$\operatorname{cin} \mathrm{Z}$ ) and is in agreement with the detection of chitin synthase activity and chitin deposition in chitin synthase mutants of $S$. cerevisiae (Bulawa et al. 1986; Sburlati and Cabib 1986; Orlean 1987; Cabib et al. 1989; Silverman 1989; Bulawa and Osmond 1990|.

Differential involvement of chitin synthase isozymes in distinct cell-wall biosynthetic functions may provide one explanation for the absence of an effect of inactivation of chs-1 by RIP on formation of cross-walls and conidia. This possibility is supported by a recent report describing the different functions of $S$. cerevisiae CHS2 and $\mathrm{CHS} 3$, which are specific for primary septum formation and the chitin ring at the bud emergence location, respectively (Shaw et al. 1991). Another possibility is that separate chitin synthase isozymes have the ability to perform the same functions. The activity of the other chitin synthases, however, is not adequate for the normal rate of assembly of the hyphal cell wall, yet it suf-
Figure 7. Comparative growth of wildtype (left; $30 \mathrm{hr}$ ) and $c h s-1^{\mathrm{RIP}}$ (right; 7 day) strains on solid Vogel's $\mathrm{N}$ medium. Growth was at $34^{\circ} \mathrm{C}$ for the times indicated. A difference in hyphal biomass as well as limited conidiation in the chs $-1^{\mathrm{RIP}}$ strain is apparent.
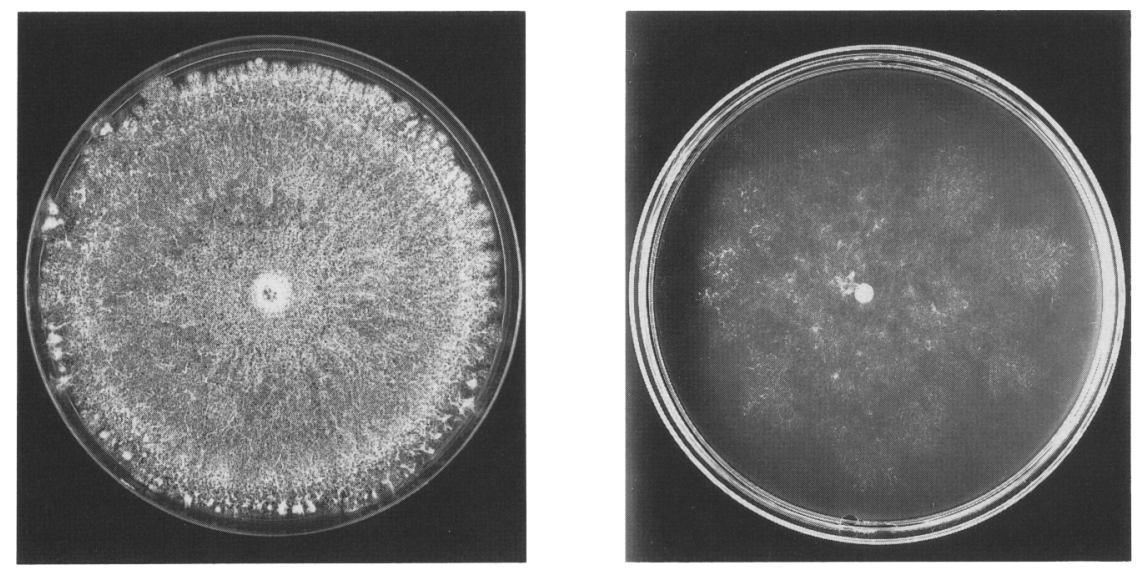

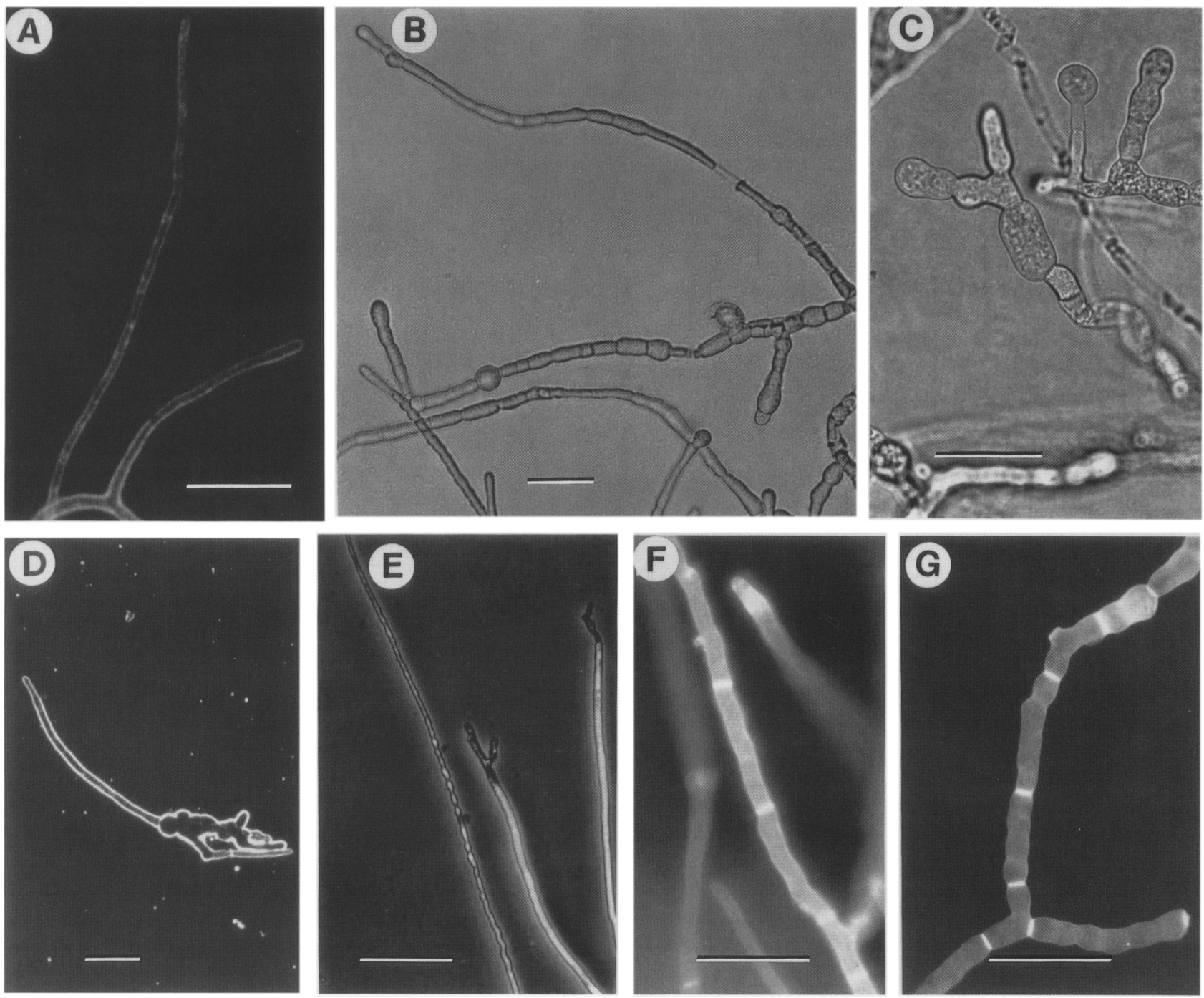

Figure 8. Microscopic analysis of hyphae of wild type $(A, F)$ and $c h s-1^{\mathrm{RIP}}(B-E, G)$ strains. $(A)$ Hyphae of a wild-type strain grown in liquid medium. $(B)$ Abnormal swelling of $c h s-1^{\mathrm{RIP}}$ strain hyphae grown in liquid culture. Swelling is evident at hyphal tips, as well as along the entire filament. Occasionally, spherical swellings are evident. $(C)$ Hyphal swelling is not uniform, although the general filamentous nature of the mycelium is maintained. $(D)$ Gross abnormalities are sometimes observed in germinating conidia (dark-field settings). (E) Degenerated aerial hyphal tips and enhanced constrictions in cultures grown on solid medium. $(F, G)$ Calcofluor staining of wild-type $(F)$ and chs-1 $1^{\mathrm{RIP}}(G)$ for visualizing chitin deposition in cross walls. Bars, $50 \mu \mathrm{m}$ in $A-G ; 20 \mu \mathrm{m}$ in $D$.

fices for formation of apparently normal cross walls and conidia.

Two chitin synthase genes have been isolated and characterized from S. cerevisiae (Bulawa et al. 1986; Silverman 1989). Two chs PCR products, different from chs-1, have been isolated from N. crassa (P. Robbins, pers. comm.). Thus, it is likely that each fungal species produces several chitin synthases. Although chs-1 is not essential, it is tempting to speculate that the different chitin synthases are primarily responsible for chitin deposition in one or more of the following processes: hyphal elongation, branching, cross-wall and/or septa formation, conidiation, and/or repair of ruptured cell walls.

\section{Materials and methods}

Strains and media

Wild-type $N$. crassa strains 74-OR23-1A (FGSC 987) and ORSa (FGSC 2490) were used in all experiments. Procedures used in growth studies, crosses, and other manipulations are described in Davis and de Serres (1970). Cultures were maintained on $1.5 \%$ agar slants containing Vogel's minimal medium $\mathrm{N}$ /Vogel 1956). When appropriate, the medium was supplemented with either hygromycin, Nikkomycin Z (both from Calbiochem), or Benomyl (DuPont) at appropriate concentrations. The drugs were filter-sterilized and added to sterile media at $\sim 50^{\circ} \mathrm{C}$. DNA transformations of $N$. crassa were carried out as described by Orbach et al. (1986). Cotransformation was performed with a 


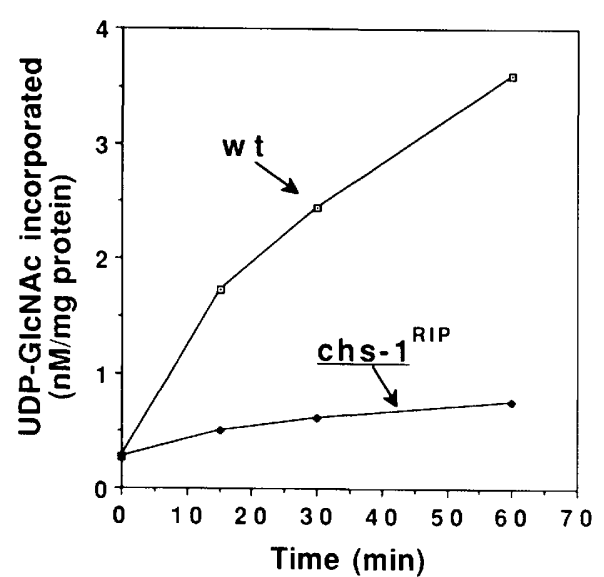

Figure 9. Chitin synthase activity of wild-type $|w t\rangle$ and chs $-1^{\mathrm{RIP}}$ cell-free extracts. Reactions were carried out at $37^{\circ} \mathrm{C}$ in 40- $\mu$ l volumes containing $35 \mu \mathrm{g}$ of protein. Incorporation of $\mathrm{UDP}\left[1-{ }^{14} \mathrm{C}\right] \mathrm{GlcNAc}$ into an insoluble product was used as a measure of chitin synthesis.

6- $\mu$ g plasmid mixture consisting of a $1: 1$ ratio of pOYA5 and pMP6 (which contains the $N$. crassa cpc-1 regulatory region lacking the two upstream open reading frames fused to the $h p h$ gene that confers hygromycin resistance; M. Plamann and C. Yanofsky, unpubl.). Hygromycin-resistant transformants were detected on regeneration medium containing sorbose as a carbon source, and single colonies were transferred to sucrosecontaining minimal agar for further analysis of hyphal morphology.

\section{Isolation and analysis of nucleic acids from N. crassa}

Genomic DNA was isolated as follows: Mycelia from cultures grown in $25 \mathrm{ml}$ Vogel's $\mathrm{N}$ medium were collected by filtration on Whatman No. 2 filter paper on a Buchner funnel. Samples were quick-frozen in liquid nitrogen and lyophilized. The dry samples were powdered by grinding and were suspended in an equal volume of lysis buffer $[50 \mathrm{~mm}$ Tris- $\mathrm{HCl}(\mathrm{pH} 8.0), 50 \mathrm{~mm}$ EDTA, $2 \%$ SDS, $1 \% \beta$-mercaptoethanol] containing $25 \mu \mathrm{g} / \mathrm{ml}$ of RNase A. After $30 \mathrm{~min}$ of incubation at $37^{\circ} \mathrm{C}, 100 \mu \mathrm{g} / \mathrm{ml}$ of proteinase $\mathrm{K}$ was added to the solution and incubation was continued for $1 \mathrm{hr}$ at $65^{\circ} \mathrm{C}$. Two phenol-chloroform $(1: 1)$ extractions were performed, followed by a single chloroform extraction, an ethanol precipitation, and a $75 \%$ ethanol wash. The DNA pellet was dried and dissolved in TE buffer $[10 \mathrm{mM}$ Tris$\mathrm{HCl}$ ( $\mathrm{pH} 7.4), 1 \mathrm{~mm}$ EDTA (pH 8.0)].
Total RNA was isolated by a slight modification of the procedure of Orbach et al. (1990). Mycelia were harvested as described above. After a quick freeze in liquid nitrogen, $25 \mathrm{mg}$ was transferred to a 2-ml screw-cap tube (Sarstedt) containing $480 \mu \mathrm{l}$ of extraction buffer $[100 \mathrm{~mm}$ Tris- $\mathrm{HCl}(\mathrm{pH} 7.5), 100 \mathrm{~mm} \mathrm{LiCl}, 10$ mM EDTA, $20 \mathrm{~mm}$ dithiothreitol], $420 \mu \mathrm{l}$ of phenol, $420 \mu \mathrm{l}$ of chloroform, $84 \mu \mathrm{l}$ of $10 \%$ SDS, and 2 grams of zirconium beads (Biospec Products Inc.). The samples were shaken twice for 30 sec in a mini-bead beater (Biospec Products Inc.). After $15 \mathrm{~min}$ of centrifugation in a microcentrifuge, the aqueous phase was transferred to a new tube and reextracted with phenol-chloroform $(1: 1)$. After an additional chloroform extraction, the RNA was precipitated, washed, dried, and dissolved in $10 \mathrm{~mm} \mathrm{Na-}$ HEPES (pH 7.5) containing $1 \mathrm{mM}$ EDTA. When RNA was to be used for RT-PCR or primer extension analyses, samples were treated with RQ1 DNase I (Promega), in the presence of $5 \mathrm{mM}$ dithiothreitol and 2.5 units of RNasin (Promega).

$N$. crassa genomic DNA (Orbach et al. 1986) and cDNA (Orbach et al. 1990) libraries were screened as described by Benton and Davis (1977). Southern blot analysis was carried out on nylon membranes (Nytran, Schleicher \& Schuell, Inc.) as described by Sambrook et al. (1989), as were all other DNA modification and cloning procedures. Bluescript (SK - ) (Strategene) was used for the cloning and preparation of various constructs. Northern blot analysis was performed as described by Orbach et al. (1990). tub-2 RNA levels were determined by probing Northern blots with a hexamer-labeled $1.2-\mathrm{kb}$ Sacl fragment isolated from pBT3 (Orbach et al. 1986). pDH25 (Cullen et al. 1987) was the source of the hph gene, encoding hygromycin phosphotransferase, which confers hygromycin resistance. This gene is driven by the Aspergillus nidulans trpC promoter region and was used as a dominant selectable marker in the isolation of $N$. crassa transformants.

Mapping of chs-1 was carried out by RFLP analysis of the small cross, according to the procedure of Metzenberg et al. (1985).

PCRs were carried out in 100- $\mu$ l reaction volumes in an Ericomp thermal cycler. Two and one-half units of Taq polymerase (Perkin-Elmer Cetus) were used in each reaction tube containing $\sim 2 \mu \mathrm{g}$ of genomic DNA as template in $50 \mathrm{mM} \mathrm{KCl}, 10 \mathrm{mM}$ Tris- $\mathrm{HCl}$ (pH 8.3), $1.5 \mathrm{~mm} \mathrm{MgCl}, 0.01 \%$ gelatin, and $200 \mu \mathrm{M}$ of each dNTP. One microgram of each primer was used for each reaction. RT-PCR was carried out using the components of the Perkin-Elmer Cetus mRNA PCR kit in accordance with the manufacturer's instructions. Oligonucleotide primers were designed with restriction sites at the $5^{\prime}$ end to facilitate cloning of PCR products (Table 1). Oligonucleotides were synthesized on an Applied Biosystems DNA synthesizer.

Primer extension analyses were performed to determine the
Figure 10. Effect of Nikkomycin $Z(A)$ and benomyl $(B)$ on growth of wild-type (open bar) and chs- $1^{\mathrm{RIP}}$ (hatched bar) strains of $N$. crassa. Inhibitors, at various concentrations, were incorporated in presterilized Vogel's $\mathrm{N}$ medium. Mycelial discs containing wild-type or chs-1 $1^{\text {RIP }}$ hyphae were placed in the center of a petri dish containing either unsupplemented or drug-supplemented solidified medium. After 12 or $50 \mathrm{hr}$, colony surface area of wild-type and chs-1 ${ }^{\text {RIP }}$ strains (respectively) grown on drug-containing medium was compared with growth area of the same strain on drug-free medium.
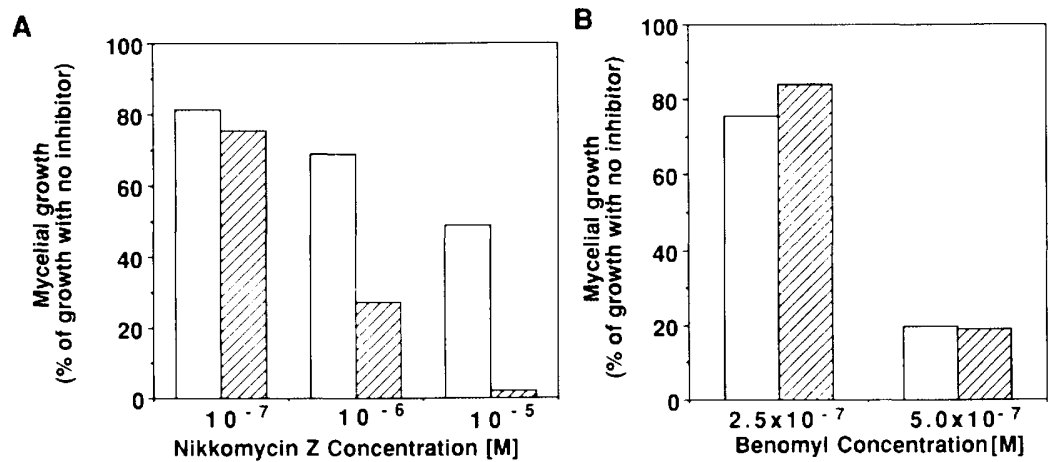
chs-1 transcription start site with two end-labeled oligonucleotide primers (Table 1), according to Sambrook et al. (1989).

\section{DNA sequencing}

DNA sequencing was performed by the dideoxy chain-termination method of Sanger et al. (1977) with $\alpha^{-{ }^{35}}$ S-labeled dATP. Sequencing reactions were electrophoresed on either $7 \mathrm{M}$ urea$1 \times$ TBE [Tris-borate EDTA (Sambrook et al. 1989)] or 6\% Long Ranger (AT Biochem) $-0.6 \times$ TBE acrylamide gels by using a BRL sequencing gel apparatus.

Clones used for sequencing were generated either by insertion of restriction fragments into the Bluescript vector or by progressive deletions from one end of a DNA fragment. The deletions were produced by using exonuclease III, as described by Henikoff (1987).

\section{Microscopy}

Samples were viewed with a Nikon Microphot FX epifluorescence microscope. For cross-wall visualization, a drop of $10 \mu \mathrm{g} /$ $\mathrm{ml}$ of Calcofluor (Fluorescent Brightener 28, Sigma) was applied to fungal samples prespotted on a microscope slide. The filter combination used was $380-$ to $425-\mathrm{nm}$ excitation, $430-\mathrm{nm}$ dichroic mirror, and 450-nm barrier. Photographs were taken with Kodak Ektachrome ASA 400 film.

\section{Chitin synthase assays}

Chitin synthase assays were performed with total fungal extracts. Extracts were prepared from 1.5- to 4-hr-old germinating conidia that were harvested by filtration /GF/C filter, Whatman). After a water wash, the germlings were placed in a 2-ml screw-cap tube containing 1.4 grams of $0.5-\mathrm{mm}$-diam. glass beads (Biospec Products). The tube was then filled with cold 100 mM HEPES ( $\mathrm{pH} 7.8$ ). The germlings were disrupted in a minibead beater, using two l-min pulses. The tubes were centrifuged for $10 \mathrm{~min}$ in a microcentrifuge, and the supernatants were collected. Protein concentration was determined by the method of Bradford (1976), with the Bio-Rad protein assay mixture.

Chitin synthase activity was monitored in $25-\mu \mathrm{l}$ reaction mixtures containing $100 \mathrm{~mm}$ HEPES (pH 7.8), $1 \mathrm{~mm} \mathrm{MgCl}_{2}, 32$ $\mathrm{mM}$ GlcNAc, and $1 \mathrm{mM}$ UDP-GlcNAc and supplemented with $1.5 \times 10^{-7} \mathrm{~mm}$ UDP $\left[1-{ }^{14} \mathrm{C}\right] \mathrm{GlcNAc}[\mathrm{sp}$. act. $300 \mathrm{mCi} / \mathrm{mmole}$ (Amersham), providing $\sim 100,000 \mathrm{dpm} /$ mixture]. Aliquots of the fungal cell-free extract used in each reaction mix contained 25 $40 \mu \mathrm{g}$ of protein. When trypsin activation of chitin synthase was examined, $2 \mu \mathrm{l}$ of a $0.2 \mathrm{-mg} / \mathrm{ml}$ trypsin (EC 3.4 .21 .4 , Sigma) solution was added to the cell-free extract before adding the other components of the assay mixture. After $15 \mathrm{~min}$ of digestion at $30^{\circ} \mathrm{C}, 2 \mu \mathrm{l}$ of a $0.3-\mathrm{mg} / \mathrm{ml}$ solution of soybean trypsin inhibitor was added to each reaction tube, followed by the components of the chitin synthase reaction mixture. Mixtures were incubated at $30^{\circ} \mathrm{C}$, and reactions were terminated by adding $25 \mu$ l of glacial acetic acid. Reaction products were separated by paper chromatography with Whatman No. 1 paper and water as solvent. Chromatographically immobile radioactivity (in chitin) was determined by liquid scintillation counting with Ready Safe (Beckman) cocktail mix and a Beckman LS3801 scintillation counter. To verify that the source of immobile radioactivity was chitin, we occasionally solubilized the product by treatment with chitinase, as described by Selitrennikoff (1979).

\section{Computer methods}

Programs of The University of Wisconsin Genetics Group were used for analysis of nucleic acid sequences (Devereux et al.
1984). The MacVector program (International Biotechnologies, Inc.) was used for Kyte and Doolittle (1982) hydrophilicity analysis. Multiple sequence alignments for comparison of predicted amino acid sequences corresponding to different chitin synthase genes were performed with the Tullal program (Subbiah and Harrison 1989!.

\section{Acknowledgments}

We thank Phillips Robbins and Sanford Silverman for communicating helpful information before publication. We thank Dan Ebbole, Ajith Kamath, Frank Lauter, and Carl Yamashiro for their critical comments on the manuscript. O.Y thanks Paul Gollnick, Barry Hurlburt, David Perkins, Matthew Sachs, and Matthew Springer for helpful suggestions during this study. O.Y. has been supported by EMBO [European Molecular Biology Organization) and BARD (United States-Israel Binational Agricultural Research and Development Fund) postdoctoral fellowships for various periods of this research. C.Y. is a Career Investigator of the American Heart Association. These studies were supported by a grant to C.Y. from the U.S. Public Health Service (GM41296).

The publication costs of this article were defrayed in part by payment of page charges. This article must therefore be hereby marked "advertisement" in accordance with 18 USC section 1734 solely to indicate this fact.

\section{Note added in proof}

The sequence data described in this paper were submitted to the Genbank/EMBL data libraries under accession number M73437.

\section{References}

Arroyo-Begovich, A. and J. Ruiz-Herrera. 1979. Proteolytic activation and inactivation of chitin synthase from Neurospora crassa. J. Gen. Microbiol. 113: 339-345.

Bartnicki-Garcia, S. 1989. The biochemical cytology of chitin and chitosan synthesis in fungi. In Chitin and chitosan (ed. G. Skjak-Braek, T. Anthonsen, and P. Sandford), pp. 23-36. Elsevier Applied Science Press, London, England.

Bartnicki-Garcia, S., C.E. Bracker, E. Reyes, and J. Ruiz-Herrera. 1978. Isolation of chitosomes from taxonomically diverse fungi and synthesis of chitin microfibrils in vitro. Exp. Mycol. 2: 173-192.

Benton, W. and R. Davis. 1977. Screening of lambda gtll recombinant clones by hybridization to single plaques in situ. Science 196: 180-182.

Bradford, M.M. 1976. A rapid and sensitive method for the quantitation of protein utilizing the principle of protein-dye binding. Anal. Biochem. 72: 248-254.

Bulawa, C.E. and B.C. Osmond. 1990. Chitin synthase I and synthase II are not required for chitin synthesis in vivo in Saccharomyces cerevisiae. Proc. Natl. Acad. Sci. 87: 74247428.

Bulawa, C.E., M. Slater, E. Cabib, J. Au-Young, A. Sburlati, W.L.J. Adair, and P.W. Robbins. 1986. The S. cerevisiae structural gene for chitin synthase is not required for chitin synthesis in vivo. Cell 46: 213-225.

Cabib, E. 1987. The synthesis and degradation of chitin. Adv. Enzymol. 59: 59-101.

Cabib, E., A. Sburlati, B. Bowers, and S.J. Silverman. 1989. Chitin synthase 1 , an auxilary enzyme for chitin synthesis in Saccharomyces cerevisiae. I. Cell Biol. 108: 1665-1672.

Cohen, E. 1987. Chitin biochemistry: Synthesis and inhibition. 
Annu. Rev. Entomol. 32: 71-93.

Cullen, D., S.A. Leong, L.J. Wilson, and D.J. Henner. 1987. Transformation of Aspergillus nidulans with the hygromycin resistance gene, hph. Gene 57: 21-26.

Davis, R.H. and F.J. de Serres. 1970. Genetic and microbiological research techniques for Neurospora crassa. Methods Enzymol. 17A: 79-143.

Devereux, J., P. Haeberli, and O. Smithies. 1984. A comprehensive set of sequence analysis programs for the VAX. Nucleic Acids Res. 12: 387-395.

Duran, A., B. Bowers, and E. Cabib. 1975. Chitin synthethase zymogen is attached to the yeast plasma membrane. Proc. Natl. Acad. Sci. 72: 3952-3955.

Glazer, L. and D.H. Brown. 1957. The synthesis of chitin in cell free extracts of Neurospora crassa. J. Biol. Chem. 228: 729742.

Gooday, G.W. 1977. Biosynthesis of the fungal cell wall-Mechanisms and implications. I. Gen. Microbiol. 99: 1-11.

. 1989. Control and inhibition of chitin synthesis in fungi and nematodes. In Chitin and chitosan (ed. G. Skjak-Braek, T. Anthonsen, and P. Sandford), pp. 13-22. Elsevier Applied Science Press, London, England.

Gooday, G.W. and A.P.J. Trinci. 1980. Wall structure and biosynthesis in fungi. Soc. Gen. Microbiol. Symp. 30: 207-252.

Gow, L.A. and C.P. Selitrennikoff. 1984. Chitin synthetase of Neurospora crassa: Inhibition by Nikkomycin, Polyoxin B and UDP. Curr. Microbiol. 11: 211-216.

Hager, K.M. and C. Yanofsky. 1990. Genes expressed during conidiation in Neurospora crassa: Molecular characterization of con-13. Gene 96: 153-159.

Henikoff, S. 1987. Unidirectional digestion with exonuclease III in DNA sequence analysis. Methods Enzymol. 125: 157165.

Hunsley, D. and G.W. Gooday. 1974. The structure and development of septa in Neurospora crassa. Protoplasma 82: 125 146.

Kang, M.S., N. Elango, E. Mattia, J. Au-Young, P.W. Robbins, and E. Cabib. 1984. Isolation of chitin synthetase from Saccharomyces cerevisiae: Purification of an enzyme by entrapment in the reaction product. /. Biol. Chem. 259: 1496614972.

Kozak, M. 1986. Point mutations define a sequence flanking the AUG initiator codon that modulates translation by eukaryotic ribosomes. Cell 44: 283-292.

- 1987. An analysis of $5^{\prime}$-noncoding sequences from 699 vertebrate messenger RNAs. Nucleic Acids Res. 15: 81258148.

Kyte, J. and R.F. Doolittle. 1982. A simple method for displaying the hydropathy of a protein. I. Mol. Biol. 157: 105-132.

Leal-Morales, C.A., C.E. Bracker, and S. Bartnicki-Garcia. 1988. Localization of chitin synthetase in cell-free homogenates of Saccharomyces cerevisiae: Chitosomes and plasma membrane. Proc. Natl. Acad. Sci. 85: 8516-8520.

Metzenberg, R.L., J.N. Stevens, E.U. Selker, and E. MorzyckaWroblewska. 1985. Identification and chromosomal distribution of $5 S$ rRNA genes in Neurospora crassa. Proc. Natl. Acad. Sci. 82: 2067-2071.

Muzzarelli, R., C. Jeuniaux, and G.W. Gooday, eds. 1986. Chitin in nature and technology. Plenum Press, New York.

Orbach, M.J., E.B. Porro, and C. Yanofsky. 1986. Cloning and characterization of the gene for $\beta$-tubulin from a benomylresistant mutant of Neurospora crassa and its use as a dominant selectable marker. Mol. Cell. Biol. 6: 2452-2461.

Orbach, M.J., M.S. Sachs, and C. Yanofsky. 1990. The Neurospora crassa arg-2 locus; structure and expression of the gene encoding the small subunit of the arginine-specific carbam- oyl phosphate synthethase. I. Biol. Chem. 265: 1098110987.

Orlean, P. 1987. Two chitin synthases in Saccharomyces cerevisiae. J. Biol. Chem. 262: 5732-5739.

Peberdy, J.F. and P.M. Moore. 1975. Chitin synthase in Mortierella viniacea: Properties, cellular location and synthesis in growing cultures. I. Gen. Microbiol. 90: 228-236.

Pless, D.D. and W.J. Lennarz. 1977. Enzymatic conversion of proteins to glycoproteins. Proc. Natl. Acad. Sci. 74: 134138.

Proudfoot, N.J. and G.G. Brownlee. 1976. 3' non-coding region sequences in eukaryotic mRNA processing intermediates. Nature 263: 211-214.

Roberts, A.N., V. Berlin, K.M. Hager, and C. Yanofsky. 1988. Molecular analysis of a Neurospora crassa gene expressed during conidiation. Mol. Cell. Biol. 8: 2411-2418.

Sambrook, J., E.F. Fritsch, and T. Maniatis. 1989. Molecular cloning: A laboratory manual. Cold Spring Harbor Laboratory Press, Cold Spring Harbor, New York.

Sanger, F., S. Nicklen, and A.R. Coulson. 1977. DNA sequencing with chain-terminating inhibitors. Proc. Natl. Acad. Sci. 74: 5463-5467

Sburlati, A. and E. Cabib. 1986. Chitin synthetase 2, a presumptive participant in septum formation in Saccharomyces cerevisiae. J. Biol. Chem. 261: 15147-15152.

Selitrennikoff, C.P. 1979. Chitin synthase activity from the slime varient of Neurospora crassa. Biochim. Biophys. Acta 571: 224-232.

Selker, E. 1990. Premeiotic instability of repeated sequences in Neurospora crassa. Annu. Rev. Genet. 24: 579-613.

Shaw, J.A., P.C. Mol, B. Bowers, S.J. Silverman, M.H. Valdivieso, A. Duran, and E. Cabib. 1991. The function of chitin synthases 2 and 3 in the Saccharomyces cerevisiae cell cycle. $J$. Cell Biol. 114: 111-113.

Silverman, S.J. 1989. Similar and different domains of chitin synthases 1 and 2 of $S$. cerevisiae: Isozymes with distinct function. Yeast 5: 459-467.

Silverman, S.J., A. Sburlati, M.L. Slater, and E. Cabib. 1988. Chitin synthase 2 is essential for septum formation and cell division in Saccharomyces cerevisiae. Proc. Natl. Acad. Sci. 85: 4735-4739.

Subbiah, S. and S.C. Harrison. 1989. A method for multiple sequence alignment with gaps. I. Mol. Biol. 209: 539-548.

Vogel, H.J. 1956. A convenient growth medium for Neurospora crassa (medium N). Microb. Genet. Bull. 13: 42-43. 


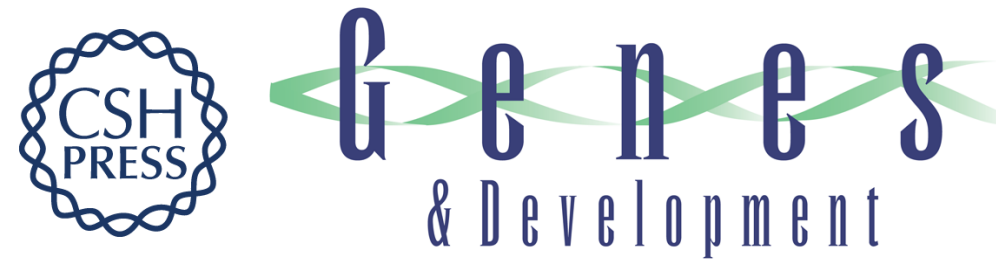

\section{Chitin synthase 1 plays a major role in cell wall biogenesis in Neurospora crassa.}

$\mathrm{O}$ Yarden and C Yanofsky

Genes Dev. 1991, 5:

Access the most recent version at doi:10.1101/gad.5.12b.2420

References This article cites 42 articles, 17 of which can be accessed free at:

http://genesdev.cshlp.org/content/5/12b/2420.full.html\#ref-list-1

License

Email Alerting

Service

Receive free email alerts when new articles cite this article - sign up in the box at the top right corner of the article or click here.

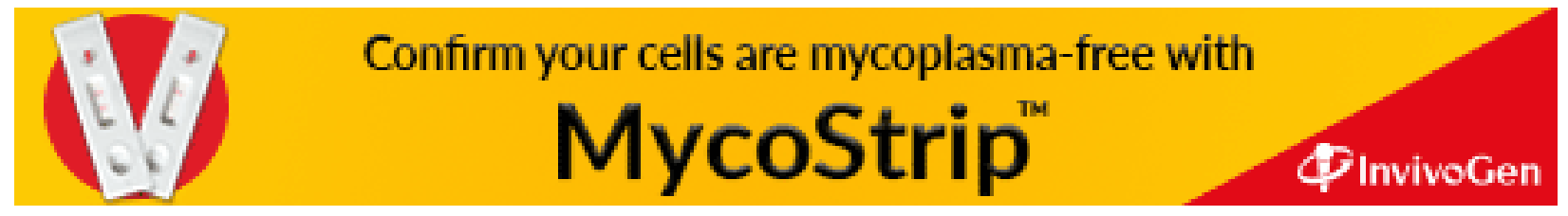

